\title{
Flare Size but Not Intensity Reflects Histamine-Induced Itch
}

\author{
Sylwia Lehmann Elyne Deuring Karsten Weller Jörg Scheffel Martin Metz \\ Marcus Maurer Tomasz Hawro
}

Dermatological Allergology, Allergie-Centrum-Charité, Department of Dermatology and Allergy, Charité - Universitätsmedizin Berlin, Corporate Member of Freie Universität Berlin, Humboldt-Universität zu Berlin, and Berlin Institute of Health, Berlin, Germany

\section{Keywords}

Axon reflex flare $\cdot$ Capsaicin $\cdot$ Cowhage $\cdot$ Histamine $\cdot$ Itch . Pruritus

\begin{abstract}
Introduction: Flare reactions arise due to the release of vasodilators from sensory nerves caused by antidromic transmission of action potentials after the induction of itch. Objective: We investigated the link between flare and itch using 3 models of itch. Methods: Skin provocations with histamine, capsaicin, and cowhage were performed in 31 subjects. Itch was quantified using the visual analog scale. Flare was assessed using laser speckle contrast imaging (LSCI) and digital photography. Results: The duration, intensity, and area under the curve of histamine-induced itch correlated with the area of increased blood flow measured with LSCI $(r=0.545, p=$ $0.002 ; r=0.575, p=0.001$; and $r=0.649, p<0.001$, respectively). Itch and skin blood flow in response to capsaicin or cowhage did not correlate. Conclusion: In histamine-induced skin inflammation, itch and increased blood flow are linked. Thus, the area of histamine-induced flare may be used as a surrogate marker for histamine-induced itch.
\end{abstract}

(c) 2020 The Author(s)

Published by S. Karger AG, Basel

\section{Introduction}

Skin flare reaction, that is, visible skin redness reflecting arteriolar dilation, involves vasodilators that are released by cutaneous sensory nerves due to their antidromic stimulation during responses to noxious stimuli [1]. This neuronal mechanism behind the flare reaction is also called the axon reflex. At the same time, local activation of sensory skin nerves and the subsequent orthodromic transmission of action potentials result in the transmission of sensory information, including itch, to the brain $[2,3]$. Considering this involvement of skin sensory nerves in both, the flare and the itch that come with skin inflammatory responses, it is conceivable that flare size and itch intensity are linked, reflecting the level of activation of sensory skin nerves.

Flare is a parameter that is readily available for objective evaluation and could be used to complement the assessment of itch intensity, which currently relies on its subjective estimation by patients. In recent years, new techniques for the assessment of skin flare responses have emerged, enabling more precise quantification of vasodilation than solely the visual assessment of skin redness. Today, flare reactions can be quantified in terms of their size and intensity, based on measurements karger@karger.com www.karger.com/spp

Karger $\stackrel{\text { ' }}{5}$

GOPEN ACCESS
(C) 2020 The Author(s)

Published by S. Karger AG, Basel

This is an Open Access article licensed under the Creative Commons Attribution-NonCommercial-4.0 International License (CC BY-NC) (http://www.karger.com/Services/OpenAccessLicense), applicable to the online version of the article only. Usage and distribution for commercial purposes requires written permission.
Tomasz Hawro

Department of Dermatology and Allergy, Charité - Universitätsmedizin Berlin Charitéplatz 1

DE-10117 Berlin (Germany)

tomasz.hawro@ charite.de 
of skin blood flow, using laser Doppler imaging (LDI), laser speckle contrast imaging (LSCI), infrared thermography, or reflectance colorimetry [3-6]. Along with this, in vivo models of experimentally induced skin inflammation and itch became well-established research tools for the identification and characterization of the pathomechanisms of itch and for the development of new antipruritic drugs [5-8]. Skin provocations with histamine and cowhage spicules represent 2 well-established experimental models of itch [9]. Histamine induces skin inflammation and itch through the activation of histamine $\mathrm{H} 1$ and $\mathrm{H} 4$ receptors (H1R and H4R, respectively) $[10,11]$. Mucunain, a protease contained in cowhage, activates protease-activated receptors 2 and 4 (PAR2 and PAR4, respectively) [12, 13]. Capsaicin, signaling through transient receptor potential vanilloid 1 , is a well-known pain inducer upon intradermal injection $[14,15]$. Its more superficial application by means of deactivated cowhage spicules has been shown to evoke itch $[16,17]$, and its application via skin prick testing (SPT) has recently been validated as a model for skin inflammation and itch [18].

As of now, there are only few studies on the relationship between experimentally induced flare and itch, and their outcomes are inconclusive or contradictory [16, 17]. Also, all of these studies are limited to the characterization of the area of flare reactions and did not analyze flare intensity, and most of them only assessed histamine-induced flare and itch $[19,20]$. As of yet, only 1 study investigated the relationship between histamine-, cowhage-, and capsaicin-induced flare and itch [16]. Also, only 2 studies employed advanced methods, such as LDI and LSCI for the assessment of the changes in skin blood flow that underlie histamine- and cowhageinduced flare responses, to assess its links to itch $[20,21]$.

A better understanding of how flare responses and itch are linked, in addition to helping research efforts, may also be of clinical relevance. Objective and precise measurements of flare responses could help determine itch intensity in patients with pruritic skin diseases. Previously, a diminished flare area has been proposed and validated as a test for the functional impairment of Cfibers in small fiber neuropathy [22]. The aim of our study was to investigate the relationship between the flare responses induced by histamine, capsaicin, and cowhage and the itch that comes with them, using LSCIbased measurements of the area of increased blood flow and blood flow intensity combined with macroscopic planimetric assessment of the flare size.

Flare Area Correlates with

Histamine-Induced Itch

\section{Materials and Methods}

\section{Study Subjects and Conduct}

The data on sensory qualities obtained in this experiment were published recently along with characteristics of the subjects and provocations [18]. Briefly, a total of 31 healthy volunteers (median age: 28 years, lower quartile 26, upper quartile 34 years; range: $20-$ 38 years; 15 females) were included in the study. Ten subjects (6 females) had a positive history for allergic rhinitis or allergic asthma. They were completely symptom free during the course of the study. Antihistamines and analgesics were not allowed for 1 week before testing. Antidepressants and corticosteroids, both systemic and topical, were prohibited at least 14 days prior to the experiment. All participants were asked to refrain from coffee consumption at least $4 \mathrm{~h}$ before skin provocations on the day of the study.

\section{Skin Challenges}

The same examiner performed skin provocations in all subjects, $15 \mathrm{~min}$ after acclimatization, in an air-conditioned study room under constant temperature $\left(22-26^{\circ} \mathrm{C}\right)$ and air humidity (40-60\%). Skin prick tests with histamine $(10 \mathrm{mg} / \mathrm{mL}$; ALK-Abello, Horsholm, Denmark), capsaicin $(0.08 \mathrm{~g} / \mathrm{mL}$ capsaicin and $48 \%$ polysorbate 80 in isotonic saline solution; Charité Pharmacy, Berlin), and their negative controls (respectively, ALK-Abello, Horsholm, Denmark, and $48 \%$ polysorbate 80 in isotonic saline solution; Charité Pharmacy, Berlin) were performed on the volar forearm [18]. A total of 40-45 active cowhage spicules and its negative control (40-45 cowhage spicules deactivated by autoclaving) were rubbed gently for $45 \mathrm{~s}$ on the skin provocation area $\left(400 \mathrm{~mm}^{2}\right)$, as described previously [9]. For all skin challenges, the negative control for the active substance was applied on the opposite forearm. Skin challenges with individual active compounds and their controls were performed at least $60 \mathrm{~min}$ apart. Provocation sites were located at least $5 \mathrm{~cm}$ apart. The randomization included the order of the provocation substance, the side of the forearm (left-right), and the provocation site (proximal-distal).

\section{Assessment of Itch}

Itch intensity was assessed on a $100-\mathrm{mm}$ visual analog scale (VAS) every minute up to $30 \mathrm{~min}$. Itch duration, peak intensity, and area under the curve (AUC) were analyzed.

\section{Assessment of the Area of Increased Blood Flow and the}

Intensity of Increased Blood Flow

LSCI was done before, 10, 20, 40, 60, and 90 min after skin provocation to assess the size of the skin area that exhibited increased blood flow and the intensity of increased blood flow. LSCI images were analyzed using dedicated software (full-field laser perfusion imager-2; moorFLPI2-Review V4.0; Moor Instruments, Axminster, UK). The principle of the measurements is described elsewhere [23]. We used a recording mode with a rate of 1 image per second. The area of increased blood flow $\left(\mathrm{mm}^{2}\right)$ was defined as the skin area on post-provocation images with a blood flux exceeding the mean flux plus 2 SD (as calculated for each site before provocation). The maximal intensity of blood flow, that is, the maximal value of post-provocation blood flux, was measured within the predefined circular area of $415 \mathrm{~mm}^{2}$ with its center in the provocation site and expressed in perfusion units. The mean value of blood flux (mean flare intensity) was measured within the area of increased blood flow and expressed in perfusion units.

Skin Pharmacol Physiol 2020;33:244-252 


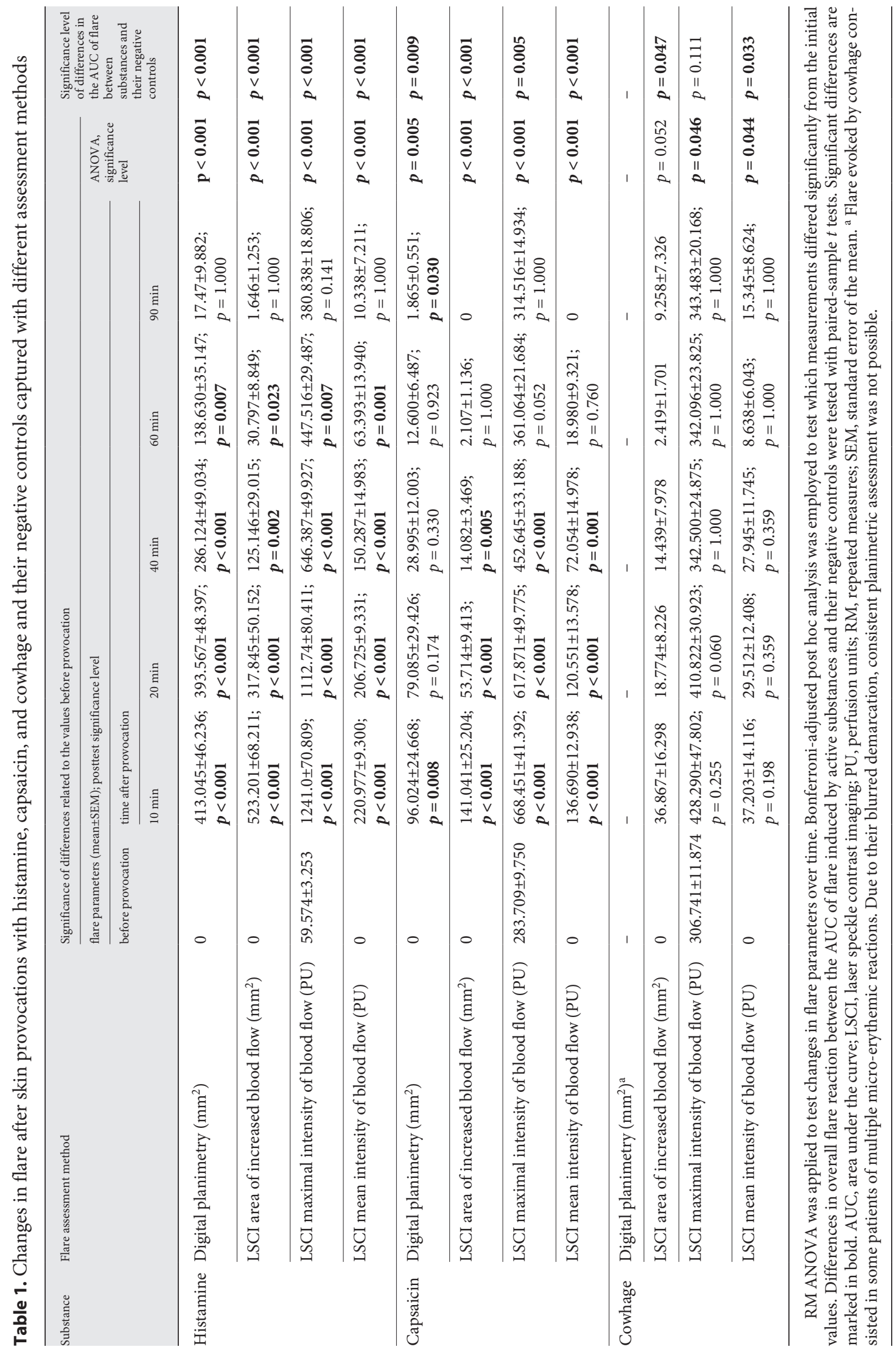



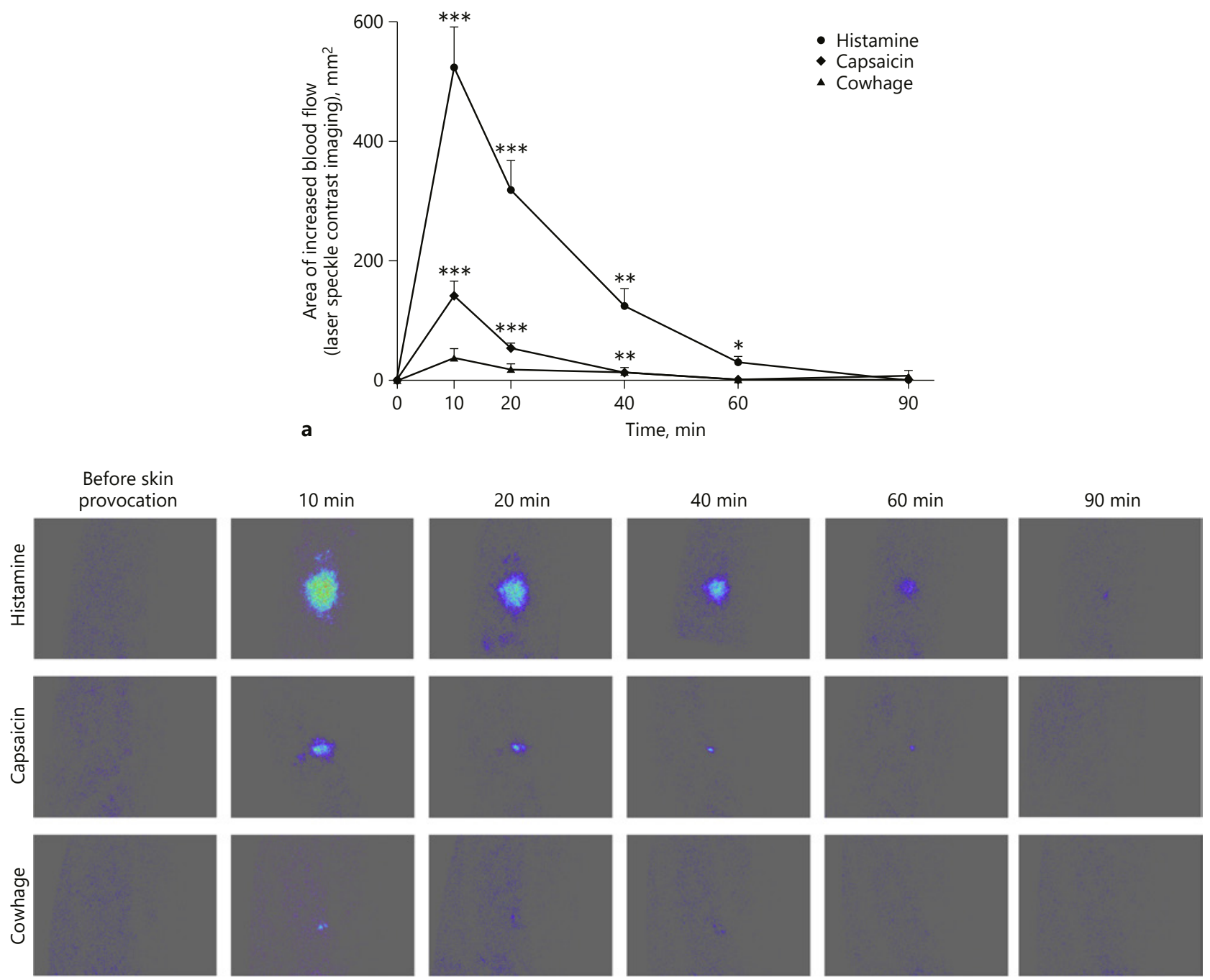

b

Fig. 1. Change in blood flow after experimental itch induction depends on the type of provocation. a Kinetic curves of increase in blood flow $\left(\mathrm{mm}^{2}\right)$ to the baseline as assessed using LSCI over the whole 90 -min observation period following skin provocations with histamine, capsaicin, and cowhage. Statistical significances $\left({ }^{*} p<0.05 ;{ }^{* *} p<0.01 ;{ }^{* *} p<0.001\right)$ are shown for comparisons between parameters before and after the skin challenge at each

\section{Assessment of Flare}

Skin imaging by digital photography was performed before, 10 , $20,40,60$, and 90 min after skin provocation. The area of the flare was determined by macroscopic quantitative planimetric morphometry from digital pictures with ImageJ software (ImageJ developers, NIH, MD, USA). The flare area was delineated manually on each picture and expressed in $\mathrm{mm}^{2}$ [6].

Flare Area Correlates with

Histamine-Induced Itch measurement time-point for active substances $(0$ - histamine, $\checkmark$ - capsaicin, $\boldsymbol{\Delta}$ - cowhage). Whiskers represent SEM. b Examples of flare development in time captured by LSCI after experimental itch induction with histamine, capsaicin, and cowhage. Subtraction of individual blood flux threshold (mean +2 SD of blood flux on the pre-provocation site). LSCI, laser speckle contrast imaging; SEM, standard error of the mean.

\section{Statistical Analyses}

Continuous variables are presented as means \pm standard error of the mean. Normality of distribution of the analyzed parameters was tested using the Kolmogorov-Smirnov test. Changes in the flare parameters over time and differences in flare parameters between itch inducers were tested with ANOVA. If the ANOVA was significant, Bonferroni-adjusted post hoc analysis test was employed to test which measurements differed significantly from the 
Table 2. Pearson's $r$ correlations between itch intensity and flare parameters measured 10 min after skin provocation with histamine, capsaicin, and cowhage

\begin{tabular}{|c|c|c|c|c|}
\hline Substance & Flare parameter & \multicolumn{3}{|c|}{ Itch parameters (Pearson's $r$, significance level) } \\
\hline \multirow{3}{*}{ Histamine } & Area of increased blood flow (LSCI) & $0.575, p=0.001$ & $0.545, p=0.002^{\mathrm{a}}$ & $0.649, p<0.001^{\mathrm{b}}$ \\
\hline & Change in maximal intensity of blood flow to baseline (LSCI) & $0.146, p=0.435$ & $0.200, p=0.280$ & $0.196, p=0.291$ \\
\hline & Mean intensity of blood flow (LSCI) & $0.053, p=0.777$ & $0.068, p=0.716$ & $0.030, p=0.874$ \\
\hline \multirow{3}{*}{ Capsaicin } & Area of increased blood flow (LSCI) & $0.127, p=0.502$ & $0.293, p=0.116$ & $0.123, p=0.516$ \\
\hline & Change in maximal intensity of blood flow to baseline (LSCI) & $0.354, p=0.051$ & $0.212, p=0.252$ & $0.271, p=0.140$ \\
\hline & Mean intensity of blood flow (LSCI) & $0.331, p=0.069$ & $0.158, p=0.395$ & $0.305, p=0.095$ \\
\hline \multirow[t]{3}{*}{ Cowhage } & Area of increased blood flow (LSCI) & $0.135, p=0.477$ & $0.031, p=0.870$ & $0.240, p=0.202$ \\
\hline & Change in maximal intensity of blood flow to baseline (LSCI) & $0.060, p=0.752$ & $-0.010, p=0.958$ & $0.048, p=0.801$ \\
\hline & Mean intensity of blood flow (LSCI) & $-0.016, p=0.934$ & $-0.029, p=0.878$ & $0.150, p=0.428$ \\
\hline
\end{tabular}

AUC, area under the curve; LSCI, laser speckle contrast imaging. Significant $p$ values are shown in bold. ${ }^{\text {a }}$ The correlation between itch duration and area of increased blood flow measured using LSCI was not significantly different from the correlation between itch duration and flare area measured planimetrically from digital pictures, $p=0.140 .{ }^{\mathrm{b}}$ The correlation between the AUC of itch intensity and area of increased blood flow measured using LSCI was stronger than the correlation between the AUC of itch intensity and flare area measured planimetrically from digital pictures, $p=0.022$.

initial values, and the least significant difference test was used for comparison between flare evoked by histamine, capsaicin, and cowhage. Paired-sample $t$ test was used to test for differences in overall flare response between the AUC of flare evoked by active substances and their negative controls. Pearson's $r$ was calculated to characterize the linear correlation between 2 continuous variables. The Hotelling test was used for comparison of overlapping correlations for dependent groups [24], and $p<0.05$ was considered significant.

\section{Results}

The Itch Induced by Histamine Is Linked to the Area but Not the Intensity of Increased Blood Flow

Histamine SPT induced itch (assessed by VAS), and it increased skin blood flow as measured by LSCI (Table 1; Fig. 1). Itch responses to histamine were significantly correlated with the size of the area of increased blood flow but not with the maximal or mean intensity of the blood flow increase as assessed by LSCI (Table 2; Fig. 2).

\section{The Itch Induced by Capsaicin or Cowhage Is Not}

Linked to the Extent or Intensity of Increased Blood

Flow

Skin provocation with capsaicin and cowhage also induced itch, albeit to a lesser extent than histamine. They also increased blood flow as assessed by LSCI, again to a lesser extent than histamine (Table 1). Histamine in- creased skin blood flow (area of increased blood flow, mean and maximal blood flow) more than capsaicin $(p<$ 0.001 , for all flare parameters) and cowhage $(p<0.001$, for all flare parameters) as captured by LSCI $10 \mathrm{~min}$ after skin provocation. Capsaicin induced larger areas of increased blood flow $(p=0.001)$ as well as a higher maximal $(p<0.001)$ and mean intensity of blood flow $(p<0.001)$ than cowhage. Importantly, itch responses to capsaicin and cowhage were not linked to changes in blood flow, neither to the size of the area of increased blood flow nor to the maximal and mean intensity of blood flow, as assessed by LSCI (Table 2).

\section{The Itch Response to Histamine Is Linked to the Size of the Visible Flare}

The itch response to histamine was significantly and moderately correlated with the size of the flare as assessed by macroscopic quantitative planimetric morphometry (Table 2). The correlation between itch intensity (AUC) and flare area was significantly weaker than the correlation of itch intensity (AUC) and the area of increased blood flow as measured by LSCI (Table 2). The size of the flare (measured by macroscopic quantitative planimetric morphometry) was strongly correlated with the area of increased blood flow (measured by LSCI) 10 min after SPT $(r=0.731, p<0.001)$. 

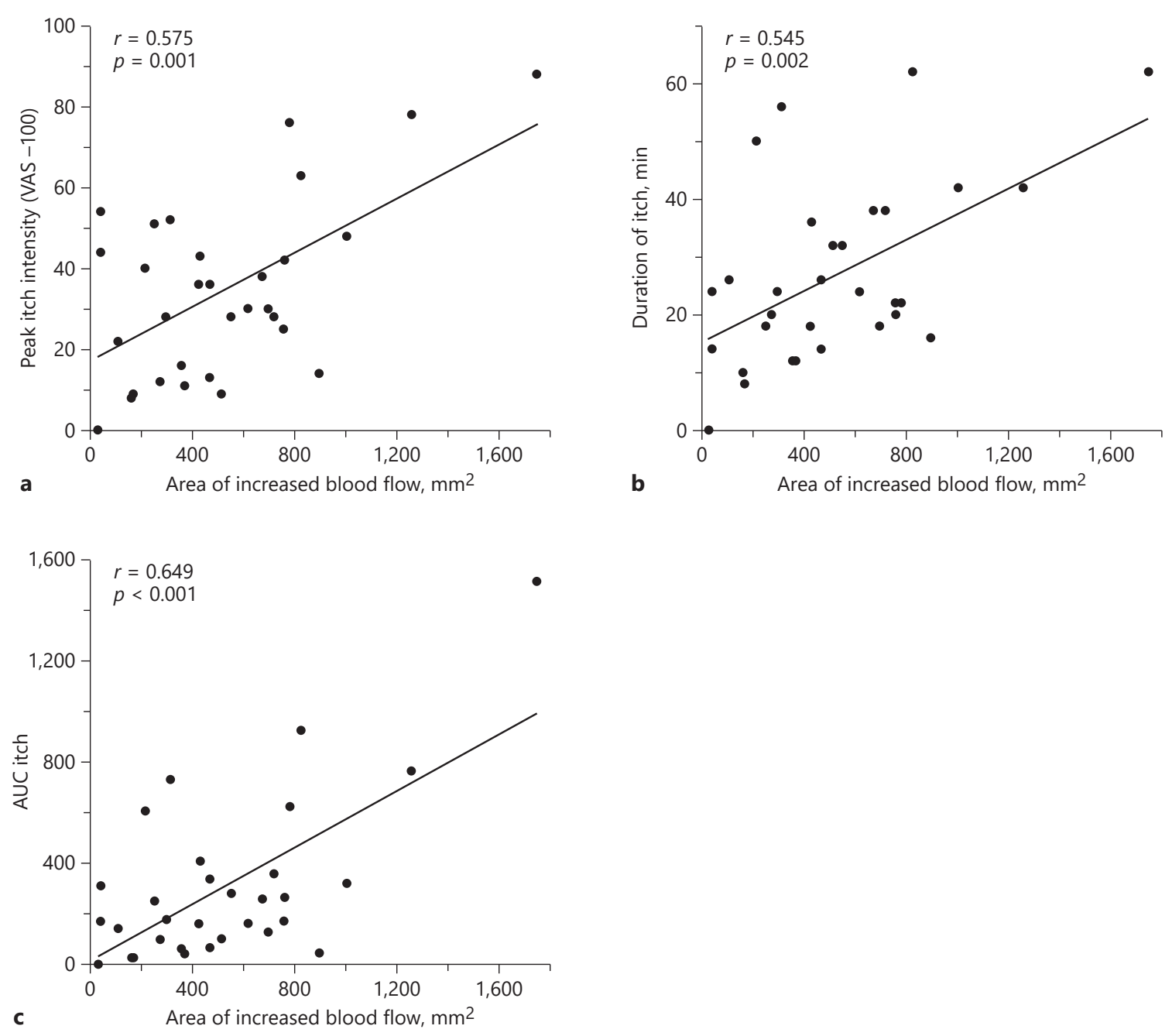

Fig. 2. Increase in blood flow correlates with histamine-induced itch. Area of increased blood flow $\left(\mathrm{mm}^{2}\right) \mathrm{mea}^{-}$ sured with LSCI 10 min after SPT with histamine correlated with peak itch intensity (a), itch duration (b), and itch AUC (c). LSCI, laser speckle contrast imaging; SPT, skin prick testing; AUC, area under the curve; VAS, visual analog scale.

\section{Discussion}

This study demonstrates that the size of the flare at sites of histamine-induced skin inflammatory responses correlates with the itch that comes with these responses. This link is best assessed by measurements of skin blood flow, but it is also evident when flare size is measured planimetrically.

The kinetics and extent of the skin responses to histamine in our study are similar to those reported previously. In line with earlier work, we observed the greatest increase in blood flow induced by histamine at the first measurement after skin provocation. The blood flow response then gradually declined within $90 \mathrm{~min}$, both in terms of its area and intensity [6]. Both the flare response and the itch induced by histamine are mediated by histamine-sensitive mechano-insensitive $\mathrm{C}$-fibers (CMi fibers) $[2,25]$. That the area of histamine-induced increased blood flow, but not its intensity, correlates with itch suggests that both reflect the activation level of the same histamine-sensitive CMi fibers. Our results are consistent with those of previous studies in which histaminergic itch correlated with flare area assessed by LSCI and LDI $[20,21]$. To our best knowledge, flare intensity has 
not yet been tested for its relationship with the intensity of experimentally induced itch.

Measuring flare reactions has previously been proposed as a test for the function of CMi fibers [26], and flare size measurements were validated for the assessment of small nerve fiber neuropathy in patients with diabetes mellitus [22]. Of note, the functional impairment of CMi fibers in patients with small fiber neuropathy was linked to a diminished flare size but not flare intensity after electrical stimulation [26] and after iontophoresis with histamine [27]. Our data are in line with this, as these previous studies and ours indicate that flare area is a more sensitive parameter than flare intensity for the function of CMi fibers $[26,27]$. The flare area depends directly on the size and functional integrity of receptive fields of the axonal tree and on fiber density $[28,29]$. In contrast, the flare intensity depends on vascular smooth muscle reactivity, the spatial distribution of the release and degradation of vasodilators such as calcitonin gene-related peptide [28]. Taken together, these data and our results suggest that the area of histamine-induced flare may be used as a surrogate marker of experimentally induced histaminergic itch. The correlations between flare size and itch parameters were moderate to strong, and they were better using LSCI than planimetry. Recording of itch using a well-established VAS or numeric rating scale is still faster and easier than using an advanced technique such as LSCI. However, assessment of itch has limitations and is prone to bias, resulting from its subjective nature [30], cultural or ethnic differences [31], and cognitive limitations in young children and elderly subjects [32]. There are application areas where subjective assessment of itch due to its limitations might be replaced or complemented by flare assessment, such as in young children, subjects with cognitive deficits, settings resulting in high subjective bias or attentional distraction, or animal studies.

The transmission of capsaicin-induced itch in humans is still not sufficiently understood. Transient receptor potential vanilloid 1 receptors are expressed ubiquitously on sensory neurons, which implies that capsaicin-induced itch may involve many classes of sensory neurons [33]. Capsaicin activates a subpopulation of mechano-heatsensitive $\mathrm{C}(\mathrm{CMH})$ fibers (i.e., quickly adapting to stepped heat stimulus CMH fibers) [34], mechano-heat-sensitive A fibers [35], and CMi fibers [36], including a subpopulation of silent nociceptors, which become responsive to heat or mechanical stimuli after sensitization, part of which may mediate itch, and which contribute to flare responses $[2,3]$. The CMi fibers due to their excessive terminal branching have the biggest innervation territo- ries, and therefore, their activation probably determines the size of histamine- and capsaicin-induced flare reactions $[2,37]$. CMi fiber activation by capsaicin is weaker than that by histamine, as shown using microneurography [36]. Therefore, it is possible that weaker activation of CMi fibers by capsaicin than by histamine results also in a smaller flare area, which we observed in our experiments and was previously reported [16]. Furthermore, the involvement of many classes of cutaneous afferents in itch evoked by capsaicin may explain the lack of correlation between flare and itch observed in our study by means of LSCI and planimetry and previously using planimetry $[16,17]$. Another explanation of the bigger flare area after histamine provocation might be a better skin diffusion of histamine than of capsaicin, resulting in reaching and activation of more nerve fibers. However, direct comparisons of diffusion and bioavailability between histamine and capsaicin are missing.

Skin provocation with cowhage is known to induce strong itch responses and minimal flare reactions $[9,16$, 38]. In our study, cowhage-induced flare reactions were also very subtle and much smaller than histamine- and capsaicin-induced flare reactions. Cowhage activates $\mathrm{CMH}$ fibers and mechano-heat-sensitive A fibers [39] but not CMi fibers [40]. The innervation areas of $\mathrm{CMH}$ fibers are approximately 3 times smaller than those of CMi fibers [37]. It has been also demonstrated that electrical stimulation of CMH fibers induces only a brief and spatially limited increase in skin blood flow as compared to electrical stimulation of CMi fibers [3]. This may explain why changes in blood perfusion induced by cowhage do not correlate with itch intensity.

Planimetric measurements of the histamine-induced flare area from digital pictures correlated with histamineinduced itch; however, this relationship was weaker than the association of itch and blood flow assessed by LSCI. Previous studies, in which flare was measured with a ruler, reported contradictory results where no [17], a weak [16], or a moderate correlation [19] between flare and itch induced by histamine was found. LSCI seems to better reflect this relationship than macroscopic quantitative planimetric morphometry, which can explain the inconsistency of these previous reports. Our observation that histaminergic itch reflects the size of flare responses is in line with clinical observations made in patients with histamine-mediated skin symptoms, for example, in patients with cholinergic urticaria where wheals come with intense itch and large erythematous flare responses [41].

It must be noted that LSCI enables continuous recording of blood flow, an advantage that was not fully taken 
in our study, due to methodological limitations of parallel recording of itch and flare. Time-matched recording of itch and flare in future studies, provided that methodology of itch rating could be adapted accordingly, could further help characterize the relationship between itch and flare. A further limitation of this study is that only healthy controls were included. Thus, extrapolation of its results to different patient groups must be done with caution, unless further studies have not investigated these relationships in patients.

Taken together, our study shows that the area of increased blood flow, but not the intensity of blood flow, correlates with histamine-induced itch. This relationship was more consistent with the use of LSCI than digital photography for flare assessment. Our findings suggest that in clinical conditions involving histamine-dependent skin reactions, the flare size may reflect itch intensity. In the experimental models of histamine-dependent itch, the flare area measured with LSCI may be used as a surrogate parameter of itch, reflecting the activation level of CMi fibers.

\section{Acknowledgements}

We would like to thank Ethan Lerner who kindly provided us with cowhage spicules. We would like to thank Janis Brusius from Moor Instruments for his outstanding support with application of the LSCI.

\section{Statement of Ethics}

This study was approved by the local Ethics Committee of the Charité - Universitätsmedizin Berlin (EA 4/063/13). All participants gave informed consent.

\section{Conflict of Interest Statement}

The authors have no relevant conflicts of interest in relation to this manuscript.

\section{Funding Sources}

This work was supported in part by the International Institute of Dermatological Allergology ( $\left.{ }^{2} \mathrm{DEAL}\right)$.

\section{Author Contributions}

S.L. analyzed the data, performed literature research, and drafted the manuscript. E.D. performed the experiments. M.Me. contributed to study conception and design. M.M. contributed to study conception and design, and drafted the manuscript. T.H. contributed to study conception and design, analyzed the data, and drafted the manuscript. All authors collaborated in retrieval of the data and data interpretation, and provided critical review and final approval of the manuscript before submission.

\section{References}

1 Chapman LF. Mechanisms of the flare reaction in human skin. J Invest Dermatol. 1977 Jul;69(1):88-97.

2 Schmelz M, Schmidt R, Bickel A, Handwerker HO, Torebjörk HE. Specific C-receptors for itch in human skin. J Neurosci. 1997 Oct; 17(20):8003-8.

3 Schmelz M, Michael K, Weidner C, Schmidt R, Torebjörk HE, Handwerker HO. Which nerve fibers mediate the axon reflex flare in human skin? Neuroreport. 2000 Feb;11(3):645-8.

4 Gibson RA, Robertson J, Mistry H, McCallum S, Fernando D, Wyres M, et al. A randomised trial evaluating the effects of the TRPV1 antagonist SB705498 on pruritus induced by histamine, and cowhage challenge in healthy volunteers. PLoS One. 2014;9(7):e100610.

5 Andersen HH, Elberling J, Arendt-Nielsen L. Human surrogate models of histaminergic and non-histaminergic itch. Acta Derm Venereol. 2015 Sep;95(7):771-7.

6 Hawro T, Lehmann S, Altrichter S, Fluhr JW, Zuberbier T, Church MK, et al. Skin provocation tests may help to diagnose atopic dermatitis. Allergy. 2016 Dec;71(12):1745-52.
7 Hawro T, Fluhr JW, Mengeaud V, Redoulès $\mathrm{D}$, Church MK, Maurer M, et al. Polidocanol inhibits cowhage: but not histamine-induced itch in humans. Exp Dermatol. 2014 Dec; 23(12):922-3.

8 Andre F, Fluhr JW, Hawro T, Church MK, Maurer M, Metz M. Characterization of cowhage-induced pruritus in inflamed and noninflamed skin. J Eur Acad Dermatol Venereol. 2020;34(1):202-6.

9 Papoiu AD, Tey HL, Coghill RC, Wang H, Yosipovitch G. Cowhage-induced itch as an experimental model for pruritus. A comparative study with histamine-induced itch. PLoS One. 2011;6(3):e17786.

10 Simons FE, Simons KJ. Histamine and H1antihistamines: celebrating a century of progress. J Allergy Clin Immunol. 2011 Dec; 128(6):1139-e4.

11 Kollmeier A, Francke K, Chen B, Dunford PJ, Greenspan AJ, Xia Y, et al. The histamine $\mathrm{H}_{4}$ receptor antagonist, JNJ 39758979, is effective in reducing histamine-induced pruritus in a randomized clinical study in healthy subjects. J Pharmacol Exp Ther. 2014 Jul;350(1):181-7.
12 Reddy VB, Iuga AO, Shimada SG, LaMotte $\mathrm{RH}$, Lerner EA. Cowhage-evoked itch is mediated by a novel cysteine protease: a ligand of protease-activated receptors. J Neurosci. 2008 Apr;28(17):4331-5.

13 Henehan M, De Benedetto A. Update on protease-activated receptor 2 in cutaneous barrier, differentiation, tumorigenesis and pigmentation, and its role in related dermatologic diseases. Exp Dermatol. 2019 Aug;28(8): $877-85$

14 LaMotte RH, Shain CN, Simone DA, Tsai EF Neurogenic hyperalgesia: psychophysical studies of underlying mechanisms. J Neurophysiol. 1991 Jul;66(1):190-211.

15 Caterina MJ, Schumacher MA, Tominaga M, Rosen TA, Levine JD, Julius D. The capsaicin receptor: a heat-activated ion channel in the pain pathway. Nature. 1997 Oct;389(6653): $816-24$

16 Sikand P, Shimada SG, Green BG, LaMotte RH. Similar itch and nociceptive sensations evoked by punctate cutaneous application of capsaicin, histamine and cowhage. Pain. 2009 Jul;144(1-2):66-75.
Flare Area Correlates with

Histamine-Induced Itch
Skin Pharmacol Physiol 2020;33:244-252 DOI: $10.1159 / 000508795$ 
17 Sikand P, Shimada SG, Green BG, LaMotte $\mathrm{RH}$. Sensory responses to injection and punctate application of capsaicin and histamine to the skin. Pain. 2011 Nov;152(11):2485-94.

18 Hawro T, Lehmann S, Deuring E, Weller K, Altrichter S, Church MK, et al. Comparison of pruritus and sensory qualities induced by capsaicin, histamine and cowhage. J Eur Acad Dermatol Venereol. 2019 Sep;33(9):1755-61.

19 Darsow U, Ring J, Scharein E, Bromm B. Correlations between histamine-induced wheal, flare and itch. Arch Dermatol Res. 1996 Jul; 288(8):436-41.

20 Andersen HH, Elberling J, Lo Vecchio S, Arendt-Nielsen L. Topography of itch: evidence of distinct coding for pruriception in the trigeminal nerve. Itch. 2017 Mar;2(1):e2.

21 Johanek LM, Meyer RA, Hartke T, Hobelmann JG, Maine DN, LaMotte RH, et al. Psychophysical and physiological evidence for parallel afferent pathways mediating the sensation of itch. J Neurosci. 2007 Jul;27(28):7490-7.

22 Caselli A, Spallone V, Marfia GA, Battista C, Pachatz C, Veves A, et al. Validation of the nerve axon reflex for the assessment of small nerve fibre dysfunction. J Neurol Neurosurg Psychiatry. 2006 Aug;77(8):927-32.

23 Briers JD. Laser speckle contrast imaging for measuring blood flow. Opt Appl. 2007;37(1).

24 Diedenhofen B, Musch J. cocor: a comprehensive solution for the statistical comparison of correlations. PLoS One. 2015;10(3):e0121945.

25 Schley M, Rukwied R, Blunk J, Menzer C, Konrad C, Dusch M, et al. Mechano-insensitive nociceptors are sufficient to induce histamine-induced itch. Acta Derm Venereol. 2013 Jul;93(4):394-9.
26 Krämer HH, Schmelz M, Birklein F, Bickel A. Electrically stimulated axon reflexes are diminished in diabetic small fiber neuropathies. Diabetes. 2004 Mar;53(3):769-74.

27 Bickel A, Krämer HH, Hilz MJ, Birklein F, Neundörfer B, Schmelz M. Assessment of the neurogenic flare reaction in small-fiber neuropathies. Neurology. 2002 Sep;59(6):917-9.

28 Geber C, Fondel R, Krämer HH, Rolke R, Treede RD, Sommer C, et al. Psychophysics, flare, and neurosecretory function in human pain models: capsaicin versus electrically evoked pain. J Pain. 2007 Jun;8(6):503-14.

29 Bickel A, Heyer G, Senger C, Maihöfner C, Maihoefner C, Heuss D, et al. C-fiber axon reflex flare size correlates with epidermal nerve fiber density in human skin biopsies. J Peripher Nerv Syst. 2009 Dec;14(4):294-9.

30 Udkoff J, Silverberg JI. Validation of scratching severity as an objective assessment for itch. J Invest Dermatol. 2018 May;138(5): 1062-8.

31 Reich A, Heisig M, Phan NQ, Taneda K, Takamori K, Takeuchi S, et al. Visual analogue scale: evaluation of the instrument for the assessment of pruritus. Acta Derm Venereol. 2012 Sep;92(5):497-501.

32 Wahlgren CF. Children's rating of itch: an experimental study. Pediatr Dermatol. 2005 Mar-Apr;22(2):97-101.

33 Ständer S, Moormann C, Schumacher M, Buddenkotte J, Artuc M, Shpacovitch V, et al. Expression of vanilloid receptor subtype 1 in cutaneous sensory nerve fibers, mast cells, and epithelial cells of appendage structures. Exp Dermatol. 2004 Mar;13(3):129-39.
34 Wooten M, Weng HJ, Hartke TV, Borzan J, Klein AH, Turnquist B, et al. Three functionally distinct classes of $\mathrm{C}$-fibre nociceptors in primates. Nat Commun. 2014 Jun;5:4122.

35 Baumann TK, Simone DA, Shain CN, LaMotte RH. Neurogenic hyperalgesia: the search for the primary cutaneous afferent fibers that contribute to capsaicin-induced pain and hyperalgesia. J Neurophysiol. 1991 Jul;66(1):212-27.

36 Schmelz M, Schmidt R, Weidner C, Hilliges M, Torebjork HE, Handwerker HO. Chemi$\mathrm{cal}$ response pattern of different classes of $\mathrm{C}$ nociceptors to pruritogens and algogens. J Neurophysiol. 2003 May;89(5):2441-8.

37 Schmidt R, Schmelz M, Weidner C, Handwerker HO, Torebjörk HE. Innervation territories of mechano-insensitive $\mathrm{C}$ nociceptors in human skin. J Neurophysiol. 2002 Oct; 88(4):1859-66.

38 LaMotte RH, Shimada SG, Green BG, Zelterman D. Pruritic and nociceptive sensations and dysesthesias from a spicule of cowhage. J Neurophysiol. 2009 Mar;101(3):1430-43.

39 Ringkamp M, Schepers RJ, Shimada SG, Johanek LM, Hartke TV, Borzan J, et al. A role for nociceptive, myelinated nerve fibers in itch sensation. J Neurosci. 2011 Oct;31(42): 14841-9.

40 Namer B, Carr R, Johanek LM, Schmelz M, Handwerker HO, Ringkamp M. Separate peripheral pathways for pruritus in man. J Neurophysiol. 2008 Oct;100(4):2062-9.

41 Jorizzo JL, Smith EB. The physical urticarias. An update and review. Arch Dermatol. 1982 Mar;118(3):194-201. 